\title{
Does Double-layer Application of a Universal Adhesive Affect Its Bonding to Different Tooth Substrates?
}

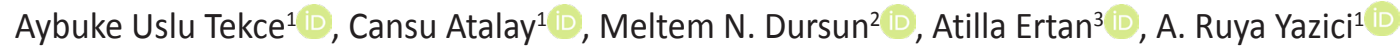 \\ ${ }^{1}$ Department of Restorative Dentistry, School of Dentistry, Hacettepe University, Ankara, Turkey. \\ ${ }^{2}$ Department of Restorative Dentistry, School of Dentistry, Firat University, Elazig, Turkey. \\ ${ }^{3}$ Department of Prosthodontics, School of Dentistry, Hacettepe University, Ankara, Turkey. \\ Correspondence Author: Aybuke Uslu Tekce \\ E-mail: aybukeuslu91@gmail.com \\ Received: $04.05 .2021 \quad$ Accepted: 10.09 .2021
}

\begin{abstract}
Objective: The aim of this study was to evaluate the effect of a single or double layer application of a Universal adhesive on bond strength to different tooth substrates.

Methods: Seventy-two extracted sound human teeth were used for the study. The teeth were divided into three groups according to tooth substrates; enamel, coronal and radicular dentin $(n=24)$. The roots of the teeth were separated from the crowns and then abraded to obtain flat surfaces. The specimens were randomly allocated into 2 groups in accordance with application layers of universal adhesive ( $n=12)$. The universal adhesive, Adhese Universal was applied in self-etch mode as single - or double-layer to different substrates. Following the adhesive application, enamel, coronal and radicular dentin substrates were restored with a resin composite (Tetric $\mathrm{N}$-Ceram). The specimens were subjected to shear bond strength (SBS) test after storage in distilled water $\left(37^{\circ} \mathrm{C}, 24 \mathrm{~h}\right)$. Representative fractured and interface samples from each group were examined by a scanning electron microscope. The data were analyzed using two-way ANOVA $(\alpha=0.05)$.

Results: There was no statistically difference in SBS values between single - and double-layer applications of the tested universal adhesive on different dental substrates $(p>0.05)$. Whilst no difference was occurred between the different dental substrates in the single-layer application ( $p>0.05)$, double-layer application on coronal dentin presented significantly higher bond strength than enamel $(p<0.05)$.

Conclusion: Double-layer application of the tested universal adhesive did not improve the bond strength regardless of different dental substrates.

Keywords: Universal adhesive, Shear bond strength, Double-layer application
\end{abstract}

\section{INTRODUCTION}

Contemporary dental adhesive systems can be categorized based on the adhesion strategies in etch-and-rinse and self-etch or the number of application steps (1). Three fundamental steps that can be either separate or combined are required to adhesion resin-based materials to the dental substrates: priming, etching and bonding. In order to shorten the treatment time, all-in-one self-etch adhesive systems have been introduced owing to decreasing the three procedures into a single process (2). Recently, the novel family of dental adhesives known as "multi-mode" or "universal", similar to the all-in-one concept but also provides a variety of uses, have been introduced to the market.

Although the etch-and-rinse strategy is still the gold standard in dentistry practice, the current trend is to improve simplified adhesive systems $(3,4)$. In spite of the fact that a significant decrease was achieved in the total treatment time and less sensitivity to dissimilarity in the clinicians' technique compared to multi-step etch-and-rinse adhesives, there are some concerns about the etching capability and vulnerable adhesive layer due to the hydrophilic nature $(5,4,6)$. Various approaches have been proposed for clinical conditions such as selective etching, hydrophobic coating, double adhesive layer applications or extended application time to overcome the deficiencies of simplified self-etch adhesives (3,7-10).

Universal adhesives, which can be considered as a new category of self-etching adhesives, are thought to have as vulnerable adhesive layers as other self-etch adhesives (11). The current trends in adhesive applications seem to be tending towards one step applications; however, it is speculated that the double-layer application might be an effective technique to improve the bonding to dentin (12).

The main difficulty for prevailing adhesive systems is to ensure a homogeneously effective bond to different tooth 
substrates such as enamel, coronal dentin and radicular dentin $(4,5)$.

Thus the aim of the present study was to assess the influence of the double-layer application of a universal adhesive on the bonding efficacy to enamel, coronal and radicular dentin. The null hypothesis purposed in this in-vitro study were that (i) the double-layer application technique of the tested universal adhesive would not influence bond strength; (ii) there would be no difference between the tooth substrates' bond strength regardless of single and double application.

\section{METHODS}

\subsection{Specimen Preparation}

Seventy-two sound, caries-free human maxillary anterior teeth extracted for periodontal reasons were included in the study. The study under a protocol (GO 20/677) was confirmed by the Ethics Committee of the local university after obtaining the informed consent of the patients. Following the disinfection in $0.5 \%$ aqueous chloramine- $T$ solution, the teeth were stored in distilled water and used within six months after extractions. To separate the roots, the crown of the teeth were sectioned along the cementoenamel junction using a slow-speed diamond saw. The teeth were then embedded in moulds with a self-curing acrylic resin and allocated into three groups according to tooth substrates; enamel, coronal and radicular dentin $(n=24)$. The buccal surfaces of the crowns were wet ground to obtain enamel and coronal dentin specimens. To prepare radicular dentin specimens, the radicular part of the teeth was abraded from the buccal surface. Afterwards, enamel and dentin were verified under the light microscope. All specimens were prepared using 180 - and 600 grit SiC papers for 60 seconds at $300 \mathrm{rpm}$ using the grinding machine (Presi Mecapol 220, Eybens, France) under running water to have a standardized smear layer.

\subsection{Adhesive Procedure}

Each substrate group was then randomly divided into two according to the adhesive's application layer $(n=12)$.

Single application: The universal adhesive, Adhese Universal (Ivoclar Vivadent, Schaan, Lichtenstein) was applied with scrubbing to each tooth substrate for 20 seconds in self-etch mode according to the manufacturers' recommendations. Then the adhesive was dispersed with oil/moisture-free compressed air until a glossy film layer. The adhesive was light-cured for 10 seconds using an LED light-curing unit (Radii Plus, SDI, Victoria, Australia) with a light intensity of $1500 \mathrm{~mW} / \mathrm{cm}^{2}$.

Double application: The adhesive was scrubbed into the tooth surfaces for 20 seconds, as in the single application, then the second layer of adhesive was exerted for another 20 seconds and light-cured for 10 seconds with the same curing unit.
The flow chart of the study is shown in Figure 1.

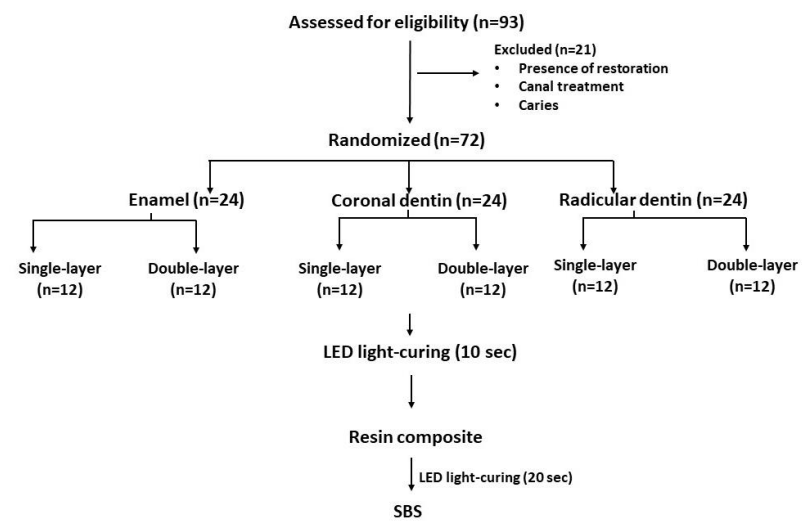

Figure 1: Flow chart of the study

\subsection{Restorative Procedure}

Following the adhesive procedure, a nano-hybrid resin composite, Tetric N-Ceram (shade A2) was placed on prepared tooth substrates through cylindrical-shaped plastic tubes (Tygon Medical Tubing Formulations 54-HL, Saint Gobain Performance Plastics, Akron, $\mathrm{OH}, \mathrm{USA}$ ) with a height of $2 \mathrm{~mm}$ and a diameter of $2 \mathrm{~mm}$. Examined under the light microscope, the coronal dentin area was determined apical to the enameldentin junction, and the radicular dentin area was determined to be apical to the enamel-cementum junction (CEJ). After the resin composite (Tetric-N Ceram) was inserted into each tube, a clear Mylar matrix strip was laid over and gently pressed and then cured with a LED for 20 seconds as instructed by the manufacturer. Table 1 lists the materials, compositions and manufacturers used in the study.

Table 1. Materials used in the study

\begin{tabular}{llll} 
Product & Product name(lot \#) & Manufacturer & Composition \\
\hline Adhesive & Adhese Universal & Ivoclar Vivadent & 10-MDP, bis- \\
& \#V13743 & Schaan, & GMA, 2-HEMA, \\
& & Lichtenstein & MCAP, D3MA, \\
& & & ethanol, water, \\
& & & initiator, \\
& & & stabilizer, silicon \\
& Tetric N-Ceram & Ivoclar-Vivadent, & Bis-GMA, UDMA, \\
Resin & Schan, & TEGDMA, Bis- \\
Composite & LT38568 & Liechtenstein & EMA, 57\% of \\
& & & filler: Barium \\
& & & glass, ytterbium \\
& & & trifluoride, mixed \\
& & & oxides and silica \\
& & & dioxide particles \\
\hline
\end{tabular}

Abbreviations: MDP, Methacryloyloxydecyl dihydrogen phosphate; HEMA, Hydroxyethyl methacrylate; Bis-GMA, Bisphenol A glycidyl methacrylate; D3MA, Decandiol dimethacrylate; MCAP,Methacrylated carboxylic acid polymer; TEGDMA, triethyleneglycol dimethacrylate. 


\subsection{Shear Bond Strength Analysis}

The specimens were stored at $37^{\circ} \mathrm{C}$ for 24 hours in distilled water, then the tubes were removed with a bistoury. After examining each sample at $10 \mathrm{X}$ magnification, specimens with any porosities or voids were excluded from the study. The specimens were attached to the fixture then tested in Instron universal testing machine (Lloyd Instruments, Leicester, UK) with a crosshead speed of $1 \mathrm{~mm} / \mathrm{min}$. The SBS data in MPa was calculated from the peak load at failure divided by the bonded surface area. Following the testing, the fractured specimens were examined under a light microscope (Olympus SZX7, Hamburg, Germany) at 40X magnification to determine the location and the type of the bond failure. The classification was assessed according to the types of failure observed in tooth substrate / composite bonding areas: a) adhesive failure, b) cohesive failure, c) mixed failure.

\subsection{Scanning Electron Microscopy (SEM) Evaluation}

One extra sample from each group was prepared to observe the resin-tooth interface using SEM. Teeth substrates were exposed, and then adhesives and resin build-ups were performed according to the same procedure previously described for each group. Samples with resin bonded were placed in self-curing acrylic resin and then separated longitudinally with a diamond saw. The exposed crosssectional interfaces were polished using high gloss abrasive discs (Kerrhawe Hiluster Plus, Kerr, CA, USA) and diamond pastes (Universal polishing paste, Ivoclar Vivadent, Schaan, Liechtenstein) were used respectively. The samples were treated with $10 \%$ phosphoric acid $(10 \mathrm{sec})$ subsequently, subjected to $5 \%$ sodium hypochlorite $(5 \mathrm{~min}$ ) followed by rinsing with distilled water.

In addition, a fractured specimen from each group was processed directly for SEM observation. Each treated specimen for SEM was dehydrated in raising degrees of tertbutyl alcohol and later conveyed from the latest $100 \%$ bath to a critical point dryer. Afterwards, each SEM specimen was coated in a vacuum evaporator with a thin gold film layer. Resin/dental substrate interfaces and fracture fields were examined by field emission SEM (FIB-SEM, GAIA3, Tescan, Oxford XMax 150 EDS).

\subsection{Statistical Analysis}

The data analysis was performed in SPSS software (21.0, SPSS, Chicago, IL). All data sets were analyzed for normality by the Kolmogorov-Smirnov test. The mean bond strength values of the independent groups were statistically analyzed by repeated-measures analysis of variance, while the twoway ANOVA test was used in dependent groups. All tests were used at the $5 \%$ significance level.

\section{RESULTS}

Mean shear bond strength (SBS) values (MPa) and standard deviations are shown in Table 2. Regardless of dental substrates, no statistically significant difference was noticed in bond strengths between the single - and double-layer applications of the universal adhesive ( $p>0.05)$.

No significant differences were found in bond strength between enamel, coronal dentin and radicular dentin in single-layer application ( $p>0.05$ ). For the double-layer application, the bond strength of coronal dentin was statistically higher than enamel's $(p<0.05)$, whereas the bond strength of radicular dentin was not statistically different from neither enamel nor coronal dentin ( $p>0.05)$.

The failure modes that occured after the SBS test performed after different adhesive layer applications were examined under a light microscope, and are shown in Table 3. Examination of double and single application interfaces under a light microscope is shown in Fig 2.

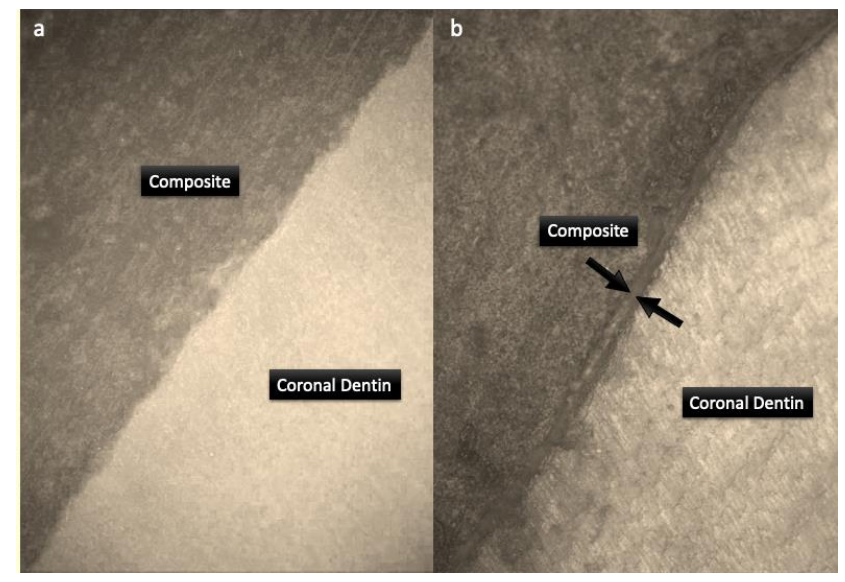

Figure 2. Light microscopy images showing restoration/coronal dentin interfaces (a) Single adhesive layer. (b) Double adhesive layer.

Representative SEM images of tooth substrate surfaces are shown in Fig. 3 (a-f). It is noteworthy that the fracture surfaces seen in the double application examples show a more homogeneous appearance than a single application. The complex distribution of enamel rods across the layer could not be viewed clearly in both double and single applications. Representative SEM images of the restorativetooth substrate interface are shown in Fig 4 (a-f).

Tablo 2. Means and Standard Deviations of the Shear Bond Strengths ( $\mathrm{MPa})$

\begin{tabular}{lcc} 
Tooth Subsrates & \multicolumn{2}{c}{ Application Number } \\
\cline { 2 - 3 } & $\begin{array}{c}\text { Single-layer Application } \\
\text { Mean (MPa } \pm \text { SD) }\end{array}$ & $\begin{array}{c}\text { Double-layer Application } \\
\text { Mean (MPa } \pm \text { SD) }\end{array}$ \\
\hline Enamel & $24.00 \pm 3.54$ & $20.58 \pm 2.14^{*}$ \\
Coronal Dentin & $36.33 \pm 7.15$ & $39.33 \pm 10.16^{*}$ \\
Radicular Dentin & $38.58 \pm 8.38$ & $35.00 \pm 6.23$ \\
\hline & \\
\hline * Indicates significant differences in vertical columns; $p<0.05$ \\
\hline
\end{tabular}


Table 3. Failure modes after SBS tests for all groups

\begin{tabular}{|c|c|c|c|c|}
\hline \multirow[b]{2}{*}{$\begin{array}{l}\text { Aplication } \\
\text { technique }\end{array}$} & \multirow[b]{2}{*}{$\begin{array}{c}\text { Tooth } \\
\text { substrates }\end{array}$} & \multicolumn{3}{|c|}{ Failure Types } \\
\hline & & $\begin{array}{c}\text { Adhesive } \\
\text { Failure } \\
(\%)\end{array}$ & $\begin{array}{c}\text { Cohesive } \\
\text { Failure } \\
(\%)\end{array}$ & $\begin{array}{c}\text { Mixed } \\
\text { Failure } \\
(\%)\end{array}$ \\
\hline \multirow{3}{*}{$\begin{array}{l}\text { Single } \\
\text { application }\end{array}$} & Enamel & 83.3 & 0 & 16.7 \\
\hline & Coronal dentin & 83.3 & 8.3 & 8.4 \\
\hline & Radicular dentin & 75 & 0 & 25 \\
\hline \multirow{3}{*}{$\begin{array}{l}\text { Double } \\
\text { application }\end{array}$} & Enamel & 91.7 & 0 & 8.3 \\
\hline & Coronal dentin & 75 & 16.7 & 8.3 \\
\hline & Radicular dentin & 83.3 & 8.3 & 8.4 \\
\hline
\end{tabular}

Percentage of specimens' fracture modes
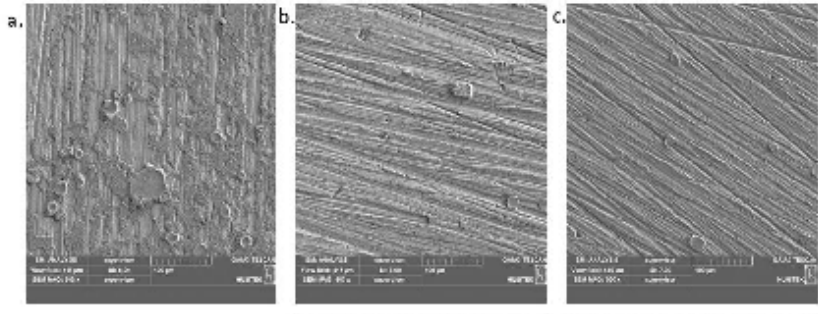

d.
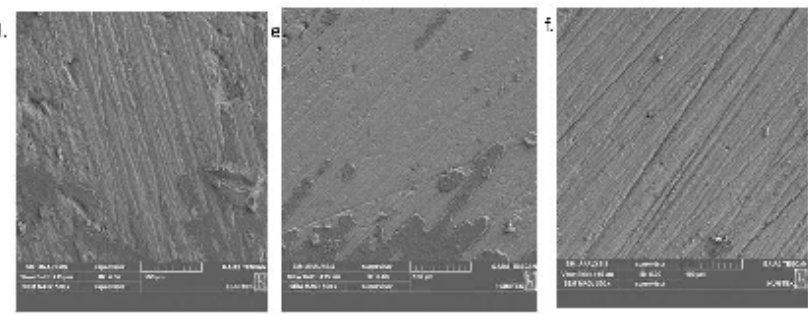

Figure 3. (a) Single application on enamel $(\times 500)$. (b) Single application on coronal dentin (x500). (c) Single application on radicular dentin (x500). (d) Double-layer application on enamel (×500). (e) Double-layer application on coronal dentin (×500). (f) Double-layer application on radicular dentin (×500).
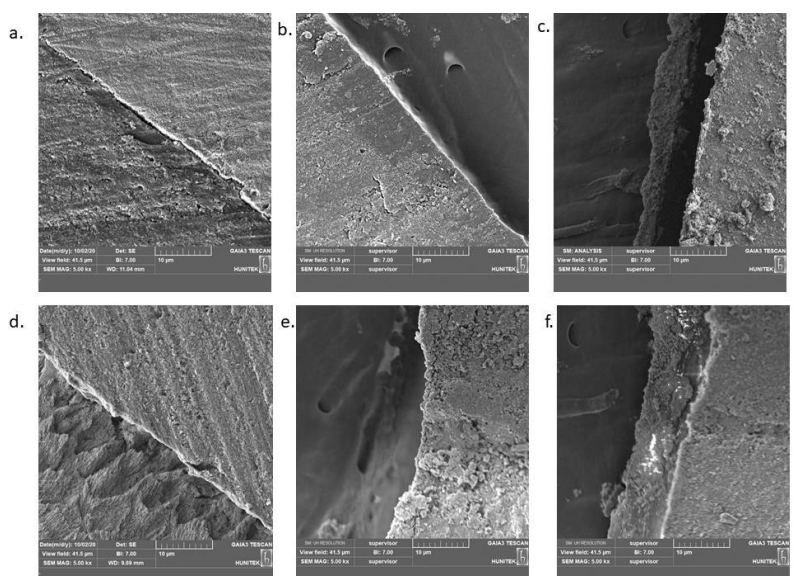

Figure 4. (a) Single adhesive layer applied restoration/enamel interface (×5000). (b) Single adhesive layer applied restoration/ coronal dentin interface (×5000). (c) Single adhesive layer applied restoration/radicular dentin interface (×5000). (d) Double adhesive layer applied restoration/enamel interface (×5000). (e) Double adhesive layer applied restoration/coronal dentin interface (×5000). (f) Double adhesive layer applied restoration/ radicular dentin interface (×5000).

\section{DISCUSSION}

Adhesive restorations are negatively affected by many physical and chemical deteriorations in the oral environment. Therefore, adhesive technology is an important factor for durable and long-lasting restorations. $(7,13)$.

In the present study as no statistically difference was found between the single - and double-layer application modes of the tested universal adhesive, the null hypothesis which a double-layer application technique of the tested universal adhesive would not influence bond strength was accepted. However, our findings are not in line with the results of previous studies that found double application of universal adhesives enhance bond strength between resin composites and tooth structure $(6,14,15)$. In an in-vitro study of Fujiwara et al. (6), it has been reported that double-application technique increased universal adhesives' bond strength to the hard structures of the tooth. This result may depend on the different compositions or layer thickness of the universal adhesives tested. In another study that examined the influence of multiple coating of adhesives on dentin bond strength, the bond strength increased until the fourth coating, yet no increase was observed when more than four coatings were applied (9). This result was found to be related to the optimum thickness of each adhesive layer however, it is not clear what this thickness was. Therefore, the possibility of the adhesive used in this study might have provided sufficient thickness of the adhesive layer in a single application, which could be considered as a reason why the extra layer did not improve the bonding (7,16-20). Moreover, the adhesive tested may have been recommended by its manufacturer for single-layer application due to achieved qualified thickness. On the other hand, some manufacturers recommend that unfilled adhesives should be applied to at least two coats $(18,21)$. Adhese Universal used in the present study is a filled adhesive containing silicon dioxide filler particles. It was indicated that filled adhesives form a thicker adhesive layer after thinning with air (22). In a controlled invitro study evaluating the bonding properties of universal adhesives to dentin, these adhesives have been reported to exhibit different bonding performances even if they shared the same multi-mode application properties (23).

Regarding the enamel substrate, there are conflicting results in terms of application numbers of adhesives $(14,18)$. While some studies reported a significant increase in enamel bond $(6,14)$, some authors reported that the double application effect differs according to the adhesive system used $(18,24)$. In a recent in vitro study, it was reported that double application increased bonding strength in enamel, unlike the current study, universal adhesives were applied with curing of the first applied layer (14). Our results are in line with previous studies that confirm double application effect on enamel bonding differs according to the specifications of the used adhesive system.

Although double application is expected to improve the quality of the adhesive layer (9), it has been reported to be less important for resin-enamel bond strength (18). Yaguchi et 
al. reported that MDP-based self-etch adhesive applications created more calcium salts in dentin than enamel (25). Yoshihara et al. (26) reported that nanolayering on dentin was remarkably improved compared to nanolayering on enamel, especially with actively scrubbing. As a result, the technique of application mode could affect dentin more than enamel (26). Although no statistical difference was noticed between the single - and double-layer application, this finding may explain the tendency to increase dentin bond strength, while no increase was observed in enamel. However, the double-layer application tended to improve the bond strength only for coronal dentin. In most of the studies, double application of adhesives increased the dentin bond strength $(6,18)$. The amplified adhesive layer might enhance the mechanical properties and as a result of this, the larger plastic zone can spread stress accumulation (10). Besides, the double-layer application may produce a more homogeneous adhesive layer and compensate for potential application deficits that occurred in the first layer $(3,21,27)$. On the other hand, Erhardt et al. (28) reported that the potential improvement in bonding strength due to changes in the application techniques of adhesives depends on the adhesive system itself. Furthermore, MDP, which is included in many universal adhesives, is different purity and quality, which affects the performance and bonding strength of the adhesive (14,29).

The discrepancy of our enamel bond strength results with previous studies might be related to the $\mathrm{pH}$ of the used adhesive system. The universal adhesive systems evaluated in the former study had variable $\mathrm{pH}$ values around 2-2.5. The tested universal adhesive, Adhese Universal has a $\mathrm{pH}$ of approximately $2.5-3.0$ which is classified as an ultramild universal adhesive (4). Within this $\mathrm{pH}$ range, adhesives in self-etch mode applied do not etch enamel as effectively as other universal adhesives (1). In a recent review, it has been declared that while prior acid etching is recommended for using universal adhesive on enamel, it is not required for dentin (4). The results of this study also support this finding. While it is said that sufficient bonding strength can be provided for dentin, prior acid-etching may be a better choice for enamel $(4,5,30,31)$.

The discrepancy of the present dentin bond strength results with previous studies might be related to the actively scrubbing. In many studies, it has been reported that when self-etch adhesives are actively applied on dentin, they can accelerate solvent evaporation hence, a higher rate of monomer impregnation into the smear layer $(3,32)$. The active application of the adhesive can lead to the transport of fresh acidic monomers into the deeper enamel and dentin, thereby enabling more aggressive demineralization and ultimately better diffusion of monomers that improve the quality of the hybrid layer $(3,18,31)$. In this study the adhesive system was applied actively, therefore a quality adhesive layer could have been achieved just with the singleapplication and caused no improvement with the double application.
The double-layer application without light curing at the first layer may be associated with the prolonged application of adhesive systems. In an in-vitro study comparing the prolonged - and immediate - applications of universal adhesives on enamel, a significant increase in bond strength was reported when using Adhese Universal with prolonged self-etching mode (33). On the other hand, in the present study, there was no statistical increase in enamel. However, the prolonged application mentioned in the study was 20 seconds as in the manufacturer's instructions (corresponding to the single-layer in this study) for Adhese Universal. In this case, applying 20 seconds as the manufacturer's instructions should not be considered as a prolonged application.

Some studies have reported that the effect of double-layer or long-term application on bonding performance is specific to the adhesive system used, especially when the adhesive system is water/ethanol-based $(28,34)$ However, the Adhese Universal system tested in the study is ethanol-based. It has been indicated that when water is added as a solvent to comonomer-ethanol mixtures, air drying or prolonged application time cannot provide better solvent evaporation since hydrogen bonding to the monomers will increase (28). It can be said that the bonding of water/ethanol-based universal adhesive, Adhese Universal, is not technically sensitive.

When considering the results of the study in terms of adhesive's application numbers, single application of the adhesive shown similar bonding performance for enamel, coronal and radicular dentin substrates, while double application mode of the adhesive showed statistically higher results for coronal dentin than enamel. Therefore, the null hypothesis which there would be no difference between the tooth substrates' (enamel, coronal and radicular dentin) bond strength regardless of the application technique (single/ double application) was partially accepted. Dentin shear bond strength of the universal adhesives might be more susceptible to application technique than enamel $(5,18)$. The adhesive layer of universal adhesives is a hydrophilic selectively permeable membrane and, as is known, dentin is formed by much more water and less hydroxyapatite than enamel. Therefore, the scrubbing action and doubleapplication of the universal adhesive could have benefits such as infiltration of the functional monomer, evaporation of the solvent/water, providing a uniform adhesive layer in the dentin $(1,8,31,35)$.

Differences such as closeness to the pulp tissue, mineral density, mineral content and direction of the dentinal tubules may cause the dentin substrate to differ in terms of regional mechanic properties (36-37). For this reason, both radicular and coronal dentin were examined in this study. However, no statistical difference was detected between these two substrates' bond strength.

According to the current literature, there is no consensus on whether double application produces higher bond strength values on adhesive systems or not $(1,3,6,7,18)$. Some methodological differences, such as whether the 
adhesive is applied passively or actively; application time or manufacturer recommendations, or application with lightcuring at the first layer should be considered $(1,3,33)$.

Additionally, as a limitation of this study, the present study was performed under in vitro conditions and only one commercial universal adhesive was tested. More studies are needed to elaborate on this subject using different adhesive systems. Moreover, the teeth used in this study are relatively older teeth with periodontal extraction indications. Different results could be obtained in young teeth. Further clinical studies should also be performed to confirm these results.

\section{CONCLUSION}

Within the limitations of the present in vitro study, for enamel, coronal and radicular dentin substrates, the double application of the universal adhesive in the self-etch mode was not effective in enhancing the shear bond strength of the tested universal adhesive. Coronal dentin bond strength of the universal adhesives might be more susceptible to application technique than enamel. Despite the longer application time, the double-layer application did not have a noticeable impact on bond strength.

Ethical approval: All procedures performed in studies involving human participants were in accordance with the ethical standards of the institutional and/or national research committee and with the 1964 Helsinki declaration and its later amendments or comparable ethical standards.

Informed consent: Informed consent was obtained from all participants included in the study who had an indication for extraction and had teeth suitable for this study.

\section{REFERENCES}

[1] Cardenas AM, Siqueira F, Rocha J, Szesz AL, Anwar M, ElAskary F, Reis A, Loguercio A. Influence of conditioning time of universal adhesives on adhesive properties and enameletching pattern. Oper Dent 2016; 41 (5):481-490.

[2] Poggio C, Beltrami R, Colombo M, Chiesa M, Scribante A. Influence of dentin pretreatment on bond strength of universal adhesives. Acta Biomater Odontol Scand 2017; 3 (1):30-35.

[3] Taschner M, Kümmerling M, Lohbauer U, Breschi L, Petschelt A, Frankenberger R. Effect of double-layer application on dentin bond durability of one-step self-etch adhesives. Oper Dent 2014; 39 (4):416-426.

[4] Rosa WL, Piva E, Silva AFd Bond strength of universal adhesives: A systematic review and meta-analysis. J Dent 2015;43 (7):765-776.

[5] Van Meerbeek B, Yoshihara K, Yoshida Y, Mine A. State of the art of self-etch adhesives. Dent Mater 2011;27 (1):17-28.

[6] Fujiwara S, Takamizawa T, Barkmeier WW, Tsujimoto A, Imai A, Watanabe H, Erickson RL, Latta MA, Nakatsuka T, Miyazaki M. Effect of double-layer application on bond quality of adhesive systems. J Mech Behav Biomed Mater 2018;77:501-509.

[7] Breschi L, Mazzoni A, Ruggeri A, Cadenaro M, Di Lenarda R, De Stefano Dorigo E. Dental adhesion review: Aging and stability of the bonded interface. Dent Mater 2008;24 (1):90-101.
[8] Perdigão J, Muñoz M, Sezinando A, Luque-Martinez I, Staichak $\mathrm{R}$, Reis $\mathrm{A}$, Loguercio $\mathrm{A}$. Immediate adhesive properties to dentin and enamel of a universal adhesive associated with a hydrophobic resin coat. Oper Dent 2014;39 (5):489-499.

[9] Hashimoto M, Sano H, Yoshida E, Hori M, Kaga M, Oguchi H, Pashley DH. Effects of multiple adhesive coatings on dentin bonding. Oper Dent 2004;29 (4):416-423

[10] Wei S, Shimada Y, Sadr A, Tagami J Effect of double-application of three single-step self-etch adhesives on dentin bonding and mechanical properties of resin-dentin area. Oper Dent 2009;34 (6):716-724.

[11] Perdigão J, Swift Jr EJ. Universal adhesives. J Esthet Restor Dent 2015;27 (6):331-334

[12] Felemban NH, Ebrahim MI. Effect of adhesive layers on microshear bond strength of nanocomposite resin to dentin. J Clin Exp Dent 2017;9 (2):e186

[13] Carvalho RM, Manso AP, Geraldeli S, Tay FR, Pashley DH. Durability of bonds and clinical success of adhesive restorations. Dent Mater 2012;28 (1):72-86.

[14] Hirokane E, Takamizawa T, Kasahara Y, Ishii R, Tsujimoto A, Barkmeier WW, Latta MA, Miyazaki M. Effect of double-layer application on the early enamel bond strength of universal adhesives. Clin Oral Investig 2021, 25:907-921

[15] Siqueira FSFd, Armas-Vega A, Izquierdo-Bucheli A, Pinto TF, Hanzen TA, Bauer J, Cardenas AFM, Loguercio AD. Does the conditioning mode and duration of universal adhesives affect the bonding effectiveness to fluorotic enamel? J Adhes Dent 2019;21:525-536

[16] Silva ALF, Lima DNL, Souza GMD, Santos CTD, Paulillo LAMS. Influence of additional adhesive application on the microtensile bond strength of adhesive systems. Oper Dent 2006;31 (5):562-568

[17] Nakaoki Y, Sasakawa W, Horiuchi S, Nagano F, Ikeda T, Tanaka T, Inoue S, Uno S, Sano H, Sidhu SK Effect of double-application of all-in-one adhesives on dentin bonding. J Dent 2005;33 (9):765-772.

[18] Albuquerque M, Pegoraro M, Mattei G, Reis A, Loguercio A. Effect of double-application or the application of a hydrophobic layer for improved efficacy of one-step self-etch systems in enamel and dentin. Oper Dent 2008,Sep-Oct;33(5):564-70

[19] Kim J-S, Choi Y-H, Cho B-H, Son H-H, Lee I-B, Um C-M, Kim C-K. Effect of light-cure time of adhesive resin on the thickness of the oxygen-inhibited layer and the microtensile bond strength to dentin. J Biomed Mater Res B Appl Biomater 2006;78B (1):115-123.

[20] Zecin-Deren A, Sokolowski J, Szczesio-Wlodarczyk A, Piwonski I, Lukomska-Szymanska M, Lapinska B. Multi-Layer application of self-etch and universal adhesives and the effect on dentin bond strength. molecules 2019,24 (2):345.

[21] Pashley EL, Agee KA, Pashley DH, Tay FR. Effects of one versus two applications of an unfilled, all-in-one adhesive on dentine bonding. J Dent 2002;30 (2):83-90.

[22] Frankenberger R, Lopes M, Perdigão J, Ambrose WW, Rosa BT. The use of flowable composites as filled adhesives. Dent Mater 2002;18 (3):227-238.

[23] Muñoz MA, Luque I, Hass V, Reis A, Loguercio AD, Bombarda NHC. Immediate bonding properties of universal adhesives to dentine. J Dent 2013;41 (5):404-411.

[24] Perdigao J, Gomes G, Lopes MM. Influence of conditioning time on enamel adhesion. Quintessence Int 2006;37 (1):35-41. 
[25] Yaguchi T. Layering mechanism of MDP-Ca salt produced in demineralization of enamel and dentin apatite. Dent Mater 2017;33 (1):23-32.

[26] Yoshihara K, Yoshida Y, Hayakawa S, Nagaoka N, Irie M, Ogawa T, Van Landuyt KL, Osaka A, Suzuki K, Minagi S, Van Meerbeek B. Nanolayering of phosphoric acid ester monomer on enamel and dentin. Acta Biomater 2011;7 (8):3187-3195.

[27] Frankenberger R, Perdigão J, Rosa BT, Lopes M. 'No-bottle' vs 'multi-bottle' dentin adhesives-a microtensile bond strength and morphological study. Dent Mater 2001;17 (5):373-380.

[28] Erhardt MC, Osorio R, Pisani-Proenca J, Aguilera FS, Osorio E, Breschi L, Toledano M, Effect of double layering and prolonged application time on MTBS of water/ethanol-based self-etch adhesives to dentin. Oper Dent 2009;34 (5):571-577.

[29] Yoshihara K, Nagaoka N, Okihara T, Kuroboshi M, Hayakawa S, Maruo Y, Nishigawa G, De Munck J, Yoshida Y, Van Meerbeek B. Functional monomer impurity affects adhesive performance. Dent Mater 2015;31 (12):1493-1501.

[30] Erickson RL, Barkmeier WW, Kimmes NS. Bond strength of selfetch adhesives to pre-etched enamel. Dent Mater 2009;25 (10):1187-1194.

[31] Loguercio AD, Muñoz MA, Luque-Martinez I, Hass V, Reis A, Perdigão J. Does active application of universal adhesives to enamel in self-etch mode improve their performance? J Dent 2015;43 (9):1060-1070.
[32] do Amaral RC, Stanislawczuk R, Zander-Grande C, Michel MD, Reis $A$, Loguercio AD. Active application improves the bonding performance of self-etch adhesives to dentin. J Dent 2009;37 (1):82-90.

[33] Sai K, Takamizawa T, Imai A, Tsujimoto A, Ishii R, Barkmeier WW, Latta MA, Miyazaki M. Influence of application time and etching mode of universal adhesives on enamel adhesion. J Adhes Dent 2018;20(1):65-77.

[34] Luque-Martinez IV, Perdigão J, Muñoz MA, Sezinando A, Reis A, Loguercio AD. Effects of solvent evaporation time on immediate adhesive properties of universal adhesives to dentin. Dent Mater 2014,30 (10):1126-1135.

[35] Ito S, Tay FR, Hashimoto M, Yoshiyama M, Saito T, Brackett WW, Waller JL, Pashley DH. Effects of multiple coatings of two all-in-one adhesives on dentin bonding. J Adhes Dent 2005;7 (2):133-141.

[36] Inoue $T$, Saito $M$, Yamamoto M, Nishimura F, Miyazaki T. Mineral density of coronal and radicular dentin. Dent Med Res 2013;33 (3):248-251.

[37] De Goes MF, Giannini M, Foxton RM, Nikaido T, Tagami J. Microtensile bond strength between crown and root dentin and two adhesive systems. J Prosthet Dent 2007,97 (4):223228.

[38] Prati C, Erickson R, Tao L, Simpson M, Pashley DH. Measurement of dentin permeability and wetness by use of the periotron device. Dent Mater 1991;7 (4):268-273.

How to cite this article: Uslu Tekce A, Atalay C, Dursun MN, Ertan A, Yazici AR. Does Double-layer Application of a Universal Adhesive Affect Its Bonding to Different Tooth Substrates?. Clin Exp Health Sci 2021; 11: 794-800. DOI: 10.33808/clinexphealthsci.932520 